\title{
Decolonising Mathematics
}

\section{K. Raju}

\section{Abstract}

Mathematics is not universal. Traditional (normal) mathematics accepts both deductive and empirical proofs like science. Colonial education replaced it with formal mathematics, the unique feature of which is not the use of reasoning but exclusion of the empirical. The coloniser never critically compared normal and formal mathematics, and tries to block such a comparison today. In Western dogma (of the church theology of reason) deduction is infallible. In fact, deduction is fallible. (1) An invalid deductive proof may be mistaken as valid. Doubts about validity can only be settled inductively. In practice, doubts are settled by invoking authority. Hence, deductive proofs are always more fallible than empirical proofs. (2) The postulates of formal math cannot be empirically checked; they are metaphysics (a metaphysics of infinity is needed even for the formal math of $1+1=2$ ). Thus, far from being eternal truths, formal mathematical theorems may not even be approximately valid knowledge. (3) Formal math dogmatically assumes two-valued logic (on the superstition that logic binds God). But logic is neither culturally universal (e.g. Buddhist logic) nor empirically certain (quantum logic). Therefore, the theorems of formal math (even if valid) are not even truths relative to postulates. Hence, colonial/formal math is inferior and should be rejected. This does not affect the practical value of math - what 'works' - which all comes from normal math which we should, accordingly, teach.

I describe two actual decolonised math courses being taught: decolonised geometry in school, and decolonised calculus in the university. Decolonised (string) geometry that is indigenous to Africa and India, is superior to the geometry currently taught in terms of conceptual clarity (points, angle, distance), ease of learning, and practical applications. Decolonised calculus teaches calculus as normal math, the way it originated in India as a 
numerical technique to solve differential equations, together with nonArchimedean arithmetic (instead of formal 'real' numbers) and zeroism (instead of limits) used to sum infinite series. Europeans stole calculus from India, and falsely attributed it to Newton and Leibniz, who failed to understand how to sum infinite series due to the Western superstition (since Plato) that mathematics is eternal truth, and hence exact. Eventually, they introduced a metaphysics of infinity allied to church dogmas of eternity - set theory, formal real numbers, and limits - as taught in university today. This metaphysics is irrelevant for any practical application of calculus, such as sending a rocket to the moon, but makes calculus very difficult. Decolonised calculus is easy, requires almost no background, and results in better science. It enables students to solve harder problems not covered in usual calculus courses. However, it excludes the ability to slip politically convenient dogmas into science through the metaphysics of formal math, and is, hence, resisted by the coloniser today.

Keywords: fallibility of deduction, postulates of formal math, decolonised geometry, decolonised calculus

\section{Introduction}

As explained in my censored article ${ }^{1}$ (Rhodes Must Fall Movement Oxford 2018: 26), decolonising mathematics involves addressing both the false history (myths) and bad philosophy (superstitions) of colonial mathematics. In this article, I address the bad philosophy of colonial (formal) mathematics.

Mathematics is not universal: the mathematics brought by colonial education replaced the traditional math taught for thousands of years (from before the Rhind papyrus). The purported 'universality' of math is thus doublespeak for a claim of the superiority of colonial math over traditional math. Is this just another spurious claim of 'superiority' like the racist claim of superiority of whites? To decide, we must examine the matter critically even though colonial education never did so and any attempt to do so today is

${ }^{1}$ The censored article is posted on my blog at http://ckraju.net/blog/?p=117. It was reproduced by many others some of whom also later took it down, but it survives in some other locations, such as The Wire, etc. See, https://thewire.in/75896/to-decolonise-maths-stand-up-to-its-false-history/. 


\section{C.K. Raju}

attacked. Colonialism cannot allow people to think critically. Instead, it indoctrinates children into that claim that 'Western math is superior' using myths, such as an elaborate falsehood about the supposed Euclid and his purported deductive proofs, neither of which exist.

The formal math which is taught today began at the turn of the $20^{\text {th }}$ century with the analysis of the 'errors' in the Elements by Russell (1897) and Hilbert (1950) and their attempts to 'fix' those 'errors' (and save the myth). This already tells us that the origins of formal math are closely linked to church texts (such as the book Elements supposedly written by 'Euclid') and myths such as the belief that it contains (or intended) deductive proofs, and the related superstitions (that deductive proofs are superior).

\section{The Double Speak about Reasoning}

Formal math is based on the dogma that 'deductive proofs are infallible, and certain, unlike empirical proofs'. We can examine this superstition irrespective of its historical roots or church origins.

First, however, it is necessary to clarify that the claim involves double speak about 'reasoning' that is taken from racist historians and planted in our school texts. For example, the official Indian school text for class IX teaches that the math that the whole world did is wrong, and inferior, and that we must imitate 'superior' Greek math as the Greeks used reasoning. Most school children interpret the remark 'Greeks used reasoning' to mean that people other than Greeks did not use reasoning. This is completely false.

Reasoning was used in the Rhind papyrus. Reasoning or inference is an accepted means of proof in all Indian systems of philosophy (the exception of the Lokayata is considered below). The Indian proof of the 'Pythagorean theorem' uses reasoning (Raju 2001). Traditional Indian texts from the $7^{\text {th }}$ century explain that the roundness of the earth is inferred from the fact that tall trees cannot be seen from afar (Lalla 1981), and that the horizon appears like a circle.

When this is pointed out, it emerges that the propaganda about the superiority of 'reasoning' refers to a special type of reasoning, called formal reasoning that is used in formal mathematics. The word 'reason' thus refers to formal reasoning which is fundamentally different from normal reasoning (used in traditional normal mathematics). 
All traditional systems used normal reasoning; that is, they accepted empirical proofs and used empirical observations as the starting point for reasoning: e.g. the roundness of the earth was inferred from the empirical observation that far off trees cannot be seen. That is, just as science does today, normal math accepted reasoning (or inference) plus empirical proofs as the basis of knowledge.

The unique feature of 'reasoning' in both church theology and formal mathematics is exclusion of the empirical. This double-speak about 'reasoning' hides a key fact: that 'reasoning' in formal mathematics means reasoning not subjected to the discipline of empirical checks. Anything can be asserted to be true without fear of being contradicted by empirical facts. This special kind of 'reasoning' should be qualified and called 'theological reasoning' to avoid confounding it with normal reasoning as most people do. 'Reasoning' in formal mathematics refers to reasoning minus any empirical inputs: the Western belief is that the empirical is fallible while deductive proof is infallible, so that any attempt to mix the empirical in a deductive proof 'weakens' it and renders it fallible. It is thus argued that 'reasoning' without empirical facts is 'superior': mathematical truths are superior to scientific truths. But is this a con?

Once we pin down the real meaning ('reasoning' = formal reasoning = exclusion of empirical) it is easy to see that deductive proofs involving formal reasoning are actually inferior and a lot more fallible than proofs based on normal reasoning.

\section{The Fallibility of Deduction}

Deductive proofs are fallible for three reasons.

\section{Errors of the Mind}

First, an invalid deductive proof may be mistaken for a valid one. The classic example is the Elements: it has not a single valid deductive proof, but Western scholars believed for centuries that it was a model of deductive proofs. This false belief persisted from 1125, when the Elements first arrived in Christian Europe from Muslim Europe, to about 1900.

This possibility of error in a deductive proof is persistent. Can the doubt be eliminated by rechecking the proof three, four or five times? No, a philosophical doubt about the validity of a deductive proof may persist like a philoso- 
phical doubt about observation. Trying to settle the doubt inductively does not eliminate doubt any more than it eliminates doubts about empirical proofs. Deductive proofs are therefore at least as fallible as empirical proofs.

However, the common practice in formal math is to rely on authority to validate a deductive proof, since the vast majority of people do not understand a formal mathematical proof. In practice, it is mathematical authority which is asserted to be infallible, like the belief that the pope is infallible. But authority is a far more fallible than empirical proofs regardless of what the coloniser says about the importance of his own authority. So, deductive proofs are actually more fallible than empirical proofs.

The Elements is not the only example. The case of the four-color theorem shows that checking the validity of complex formal proofs is often beyond almost all mathematicians. Computer-generated formal proofs may soon become so complex that no human can be sure if any complex deductive proof is valid. So much for the purported infallibility of deduction.

Everyone accepts that empirical proofs are fallible due to possible errors of the senses (the classic example in Indian philosophy is that one might mistake a snake for a rope or vice versa). However, the above fallibility of pure deductive proof relates to errors of the mind. Unlike the senses which err occasionally, the human mind invariably errs when asked to perform a complex mental task of deduction in real time, such as playing a game of chess. The errors are clear from the fact that computers invariably beat ALL humans in chess. The mind is far more fallible than the senses (especially when there is no sensory input to discipline its fantasies).

Fallibility is especially true of an indoctrinated mind (such as that of Westerners during the 'Dark Ages', the Crusades and the Inquisition) or the captured mind of the colonised. Like the church, colonialism used indoctrination of the mind as a key tool of political power. Hence, such 'errors of the indoctrinated mind', as happened in the case of the Elements, are far more persistent than errors of the senses. The error about a rope/snake is quickly resolved in practice by prodding the rope/snake with a stick, repeatedly if necessary. The elementary error about purported 'deductive proofs' in the Elements took almost eight centuries to resolve (and this falsehood is still being taught in Indian schools). Frequent and persistent errors of the mind in mistaking invalid deductive proofs for valid ones show that deductive proofs are more fallible than empirical proofs. That means that the coloniser's formal math is inferior to normal math and, consequently, must be rejected. 


\section{Deductive Proof Does Not Lead to Valid Knowledge}

Second, pure deductive proofs (disjointed from the empirical) are fallible as they do not lead to valid knowledge. A postulate is always the first sentence of a formal proof. The exclusion of the empirical from a proof means it must also be excluded from the postulate. Therefore, a proof may begin with empirically faulty premises. We have already seen an example above: Russell began with the faulty premise that the author of the Elements intended deductive proofs, and reached the faulty conclusion that it was the author who erred (and not the myths about the author, which were false). Russell could have avoided this error had he tried to cross-check who the real author was, based on empirical evidence.

But Russell celebrated the fact that formal math is metaphysics. He asserted 'We ... take any hypothesis that seems amusing, and deduce its consequences. ... Thus [formal] mathematics may be defined as the subject in which we never know what we are talking about, nor whether what we are saying is true' (Russell 1917: 46 e.a.).

It was to drive this point home that 'deduction minus the empirical' leads to awful errors, that I gave the example of a rabbit with horns in my censored article ${ }^{2}$. The example went as follows. 1. All animals have two horns. 2. A rabbit is an animal. 3. Therefore, a rabbit has two horns. This is a valid deductive proof, a model example of modus ponens, but the conclusion is invalid knowledge because the premise (1) is empirically faulty. But, as Russell explained, this is irrelevant; what matters is that the hypothesis must be amusing, and I find the hypothesis that all animals have two horns distinctly amusing.

The Lokayata used a 'rabbit's horns' and a 'wolf's footprints' to illustrate the fallibility of deduction: by seeing a wolf's footprints (Suri 2000) villagers wrongly infer that a wolf was around. This is an error, as in actual fact the wolf's footprints were made by a man to demonstrate that inference may lead to defective knowledge as it may be based on empirically false premises.

\subsection{Deductive Proof Helps Impose Authority}

This fallibility of 'reasoning', due to the absence of the empirical, greatly suited church politics, for by selecting appropriate premises (on the strength

${ }^{2}$ See, also, 'Mathematics and censorship'. https://kafila.online/2017/06/25/mathematics-and-censorship-c-k-raju/. 
of authority), one can deduce as a formal mathematical theorem absolutely any conclusions one likes. This method of using metaphysics to reach politically convenient conclusions is widespread. Today, mathematics is applied to a variety of fields, from cosmology to economics, and slipping in appropriate authoritative postulates results in persuasive, politically convenient conclusions that are detrimental to the colonised. Concrete examples are Kenneth Arrow's impossibility theorem in economics, or the creationism of Stephen Hawking's singularity theory (Raju 2003). Arrow's impossibility theorem goes against the common belief that the good of the many must prevail over the good of a few. This is put forward as a 'rigorous' mathematical theorem (aka eternal truth) and influences the economic policies of the colonised to their detriment. In a recent debate on decolonisation, it was pointed out that Hawking's singularity theory was used to claim the absurdity that physics has proved the truth of Judeo-Christian theology. Noticeably, the postulates used in formal mathematics, as taught today, are invariably those laid down and approved in the West: calculus is taught with formal real numbers, never with Indian non-Archimedean arithmetic.

\subsection{The Postulates of Formal Mathematics are not Based on Experience}

The postulates of formal mathematics are NOT based on experience. They cannot be. All these postulates, including those required to prove $1+1=2$, involve a metaphysics of infinity; hence, they cannot be empirically checked. They are irrefutable metaphysics, not falsifiable on Popper's criterion. Hence, no computer can ever do formal Peano arithmetic because this involves a metaphysics of infinity; computers use ints (computer data types) instead.

Likewise, while real numbers are declared essential to calculus, and there is supposedly an uncountable infinity of irrational real numbers, no one can even write a single irrational real number exactly. Hence, computers, which must work with reality not fantasy, use floating point numbers.

Historically, the need for this metaphysics arose from the Western superstition that mathematics is exact, since it is eternal truth. Recall that Plato and the Neoplatonists thought that mathematics most easily arouses the eternal soul (by sympathetic magic) since it contains eternal truths. Although the church later cursed the Platonic and 'Neoplatonic' ('pagan') notion of soul, superstitious belief in the eternal truths of mathematics persisted, as in the 
Thomist superstition that the 'eternal laws of nature' are written in the language of mathematics which embodies eternal truths. Westerners believed that mathematics must hence be exact, since the slightest error would be exposed at some time or the other during eternity. This superstitious belief in the exactitude of mathematics could not be reconciled with the highly practical value of the infinite series of the Indian calculus to derive the precise (but not exact) trigonometric values required for navigation (on which European dreams of wealth rested). This led Descartes and Galileo to reject infinite series. Descartes reasoned that the exact sum of an infinite series was beyond the human mind. However, the practical value of approximate sums of infinite series was overwhelming. Therefore, Newton imagined a metaphysical way of summing infinite series, which resulted in his absurdly confused doctrine of fluxions for calculus (See Raju 2003; 2006a; 2006b; 2007; 2015).

On the strength of these non-empirical postulates about infinity, formal math erects a fantasy world where various things may be proved. While, as Russell (1917) emphasised, formal math has neither truth nor meaning, some propositions may be so interpreted as to be valid, but the postulates about infinity may and do lead also to absurd conclusions. This is not restricted to the conclusions of Hawking and others. Thus, most formal math nowadays is done using set theory. The postulates of set theory lead to the Banach-Tarski paradox: contrary to reality, the belief that a ball of gold can be divided and reassembled into two identical balls of gold and so on, to obtain innumerable balls of gold from one! Hence, a formal mathematical proof provides no guarantee of epistemic certainty (or even epistemic probability) despite claims of 'rigour'.

\section{A Formal Mathematical Theorem is Not Certain Truth Even Relative to Postulates}

Third, deductive proofs are fallible because the logic used for deductive proof may not correspond to reality (Raju 2001). In an attempt to reduce mathematics to logic, Russell naively assumed (as his fellow Western philosophers had done for centuries) that logic is of one kind only-the two-valued logic attributed, without evidence, to Aristotle, naively conflating Aristotle of Toledo (based on $12^{\text {th }}$ century Arabic texts) with the Aristotle of Stagira (Raju 2008). This building of vast philosophies on naive historical premises is a habit of Western philosophers; Kant also built his doctrines of reason on the false premise that 


\section{C.K. Raju}

logic started with Aristotle and has not changed, and hence, has reached a state of perfection! (Kant 1996).

\subsection{Alternative Logics}

However, the fact is that logic is not unique. Long before even the historical Aristotle of Stagira, India had many systems of logic, such as Buddhist catuskoti, Jain syadavada, and the two-valued logic of Naiyayikas. In the Brahmajala sutta, of the Digha Nikaya, the Buddha accuses an opponent of wriggling like an eel, since he uses an eight-valued logic (Raju 2008).

If we use a different logic the theorems of formal mathematics (from the same postulates) will change. So, formal mathematics is not even certain relative truth relative to postulates, as is wrongly believed. It is, at best, fallible, relative truth - relative to both postulates AND a particular logic chosen from among an infinity of different possible ones.

As usual, the West lagged millennia behind, and became acquainted with other logical systems only after the 1930s. This issue is not merely one of 3-, 4-, or more valued logic: Buddhist logic, like quantum logic (Raju 1994), is not even truth-functional. Consequently, proofs by contradiction fail. Why should the colonised pay the price of Western ignorance and backwardness by imitating the West?

The uncertainty of logic is an additional reason why no epistemic certainty can be attached to pure deductive proofs: which logic to use for deduction can only be decided empirically by induction! As usual, the only answer that Westerners have had to this objection, in the past two decades, is to keep striking a pose of superiority and denounce the authors - that is the ultimate Western syllogism! It is time to topple this colonial pose of superiority by laughing at it.

\subsection{Rational Theology and 2-valued Logic}

As I have explained elsewhere (Raju 2006a), the reason for this Western parochialism about logic is the church dogma that logic binds God, a dogma which did not ask the obvious question: which logic binds God? As I have further explained, the dogma of Christian rational theology was derived from misunderstanding a casual concession made to Islamic rational theology by al Ghazali, that Allah is bound by logic (but not by cause and effect). 
Nevertheless, today the demand is that, through formal mathematics, the world must remain bound by those incorrect church dogmas.

\subsection{Quantum Logic}

I emphasize that the argument for other logics does not come from culture alone: quantum logic is not two valued, or even truth-functional, and the empirical world is certainly quantum mechanical at the microphysical level. An electron may empirically be both here and there ('not-here'). This 'inconsistency' does not trivialise the world in the way an inconsistency trivializes a formal mathematical theory. That is, logic has to be empirically determined. Consequently, any purely logical proof (based on any logic) is always weaker than empirical proof. 'Deductive proofs' are inferior and not superior, which means formal math should be abandoned.

\subsection{Summary}

To summarise, pure deductive proofs (excluding the empirical) are more fallible than empirical proofs, for three reasons: (1) an invalid deductive proof may be mistaken for a valid one; the indoctrinated mind is far more easily deceived than the senses. (2) If the postulates are not empirically tested, they may lead to nonsensical conclusions. There is no way to empirically validate the postulates of formal mathematics which involve a metaphysics of infinity; one must rely on authority. This helps to insert authoritatively approved (and politically convenient) fictions into various applications of mathematics including science. (3) Formal mathematics is founded on a superstitious belief in the universality of logic, whereas logic is neither culturally universal nor empirically certain (though it is pretty certain that 2 -valued logic is only approximately the case at the macrophysical level).

So, the colonised must abandon formal mathematics, and also start isolating and weeding out the political consequences of formal mathematics inserted into economics and science.

\section{'It Works'}

Though the colonised mind is unable to contest any of these arguments against 


\section{C.K. Raju}

formal math, it doggedly persists in defence of its missionary indoctrination by piling on the guesswork based on stories. A common response to doubt is: 'it works'.

But what works? To reiterate, the practical value of math all relates to normal math. There is a general reason for this: all practical and real-world applications must involve the empirical. For example, how and where does the Pythagorean theorem work? It certainly does not hold exactly on the earth, for its surface is curved. Not in space either, for space too is curved. At best, it works as an inexact approximation. But, if the Pythagorean theorem can be applied only as an inexact approximation, then why reject the empirical (normal math) proof of the Pythagorean theorem?

This matter may be clarified by way of an analogy. Suppose one has an ailment such as arthritis, and a quack were to give one a powder and recite a chant and we find 'it works', what would one do? Uncritically accept the whole package or investigate the active ingredient? It may be that the chant is irrelevant and that the powder consists of crushed steroid pills, well-known to work for arthritis.

Something similar happens in the case of 'practical applications' of formal math: the only active ingredient is normal math. This argument applies to all formal math related to mathematics of practical value. The practical value pre-existed. A good way to clarify this is by examining the real history of mathematics.

Europeans' backwardness in elementary arithmetic made them backward in all other aspects of practical math: medieval and renaissance Europe was 3000 years behind Africa. Consequently, Europeans imported not only arithmetic, but also virtually all the practical mathematics taught in school today: algebra (Colebrooke 1817), trigonometry, calculus (Raju 2007), and probability and statistics (Raju 2011a). They did so in order to reap the benefits of the practical value of that math: arithmetic for commerce, calculus and trigonometry for navigation, and probability to make money in games of dice, amongst a host of others. More specifically, the infinite series of the calculus was imported from Cochin for its usefulness in deriving the precise trigonometric values required for European navigation (Raju 2007). Even in Europe, the practical value of calculus existed long before formal real numbers, set theory or limits, which are today deemed 'essential' for calculus. That same practical value (through numerical solution of differential equations) also persists to this day (as in calculating the trajectories of rockets and spacecraft). 
Indeed, the practical value is obtained by using computers which cannot use real numbers.

Thus, all that the West did was to add a redundant layer of metaphysics to a pre-existing normal math, which added nothing to its practical value. The metaphysics involved a particular conceptualisation of infinity which suited (and still suits) church dogmas of eternity (Raju 2015). This normal math, wrapped in a metaphysics of infinity, and bundled with a false history (e.g. 'Newton and Leibniz invented the calculus') was declared 'superior' and returned to the colonised through colonial education. Under the influence of such education, the colonised accepted the claim without critically examining any aspect of it.

For those who do not know calculus or how rocket trajectories are calculated today, an easy analogy might assist in understanding the process by which the coloniser first learnt from the colonised, and then gave back a slightly altered product, declaring it to be superior. The game of chess went from India to Persia, as documented in Firdausi's Shahnama, and then on to Arabs, eventually reaching Europe. But, when it returned to India with the British, the king had acquired a symbolic cross on his head, the camel had been renamed 'bishop', and the rules of the game had changed. These new rules were declared 'internationally accepted' (= colonially authorised). Obviously, the cross on the head of the king is dispensable and irrelevant to the game, and the rules can always be changed back if we wish. The colonised must do that in math by reverting to normal math.

To summarise, the claim of colonial, white superiority in math has never been properly argued. It cannot be, because the white coloniser started off as inferior. Just as no Western historian could provide any evidence for Euclid, no Western philosopher has addressed my objections to formal mathematics in the past two decades. When pressed, they resort to the classical techniques of forcibly suppressing the critique by means of censorship, or witch-hunting, and other ways of disparaging and silencing the critic. This is an admission of total intellectual defeat by the West, and a signal to proceed with the decolonisation of mathematics.

Let us now examine two concrete examples of how mathematics can be and has been decolonised in school and university. Decolonisation in math - geometry and calculus - has been tried out both as pedagogical experiments and as regular university courses. 


\section{Decolonised Math 1: Geometry}

The West imported African/Egyptian (religious) geometry through the Greeks (Plato and others). As noted above, the imported geometry was modified: reinterpreted by the church to fit its doctrine of persuasion by reason for use by missionaries. (The church needed this doctrine of reason, aka Christian rational theology, in the $12^{\text {th }}$ century due to the military weakness of the Christian part of Europe compared to Muslim Europe, which accepted Islamic rational theology.) To enable church use, it was packaged with a false history of theologically-correct Greek origins (Euclid).

However, the Egyptians also had a practical geometry which is still in use across Africa. We find this depicted on the east wall of the tomb of Djeserkaseneb (or Djeserkareseneb) at Luxor (for an image see Clagett 1999). For practical geometry such as measuring the area of a field (to estimate crop yield and tax) Egyptians used a rope (or cord), and the cord bearers were called 'rope stretchers' or harpedonaptae in Greek.

We do not know how exactly Egyptians did cord geometry. However, a similar indigenous tradition of string geometry, the sulba sutra-s, exists in Indian tradition, and is reasonably well-documented (by masons, not mathematicians). Presumably, the two traditions of rope geometry (Indian and African) were similar as is evident in Herodotus' observation that ancient Egypt and ancient India had many things in common (such as the notion of soul also used by Plato, and in early Christianity, or the festival of lamps, or the tendency to take frequent baths to prevent infection). Rajju ganit, or calculations with the rope, was a standard part of math education in precolonial India.

String geometry ${ }^{3}$ differs from school geometry as currently taught, both philosophically and in the use of a different instrument (a string) from those found in the school geometry box.

The philosophical difference is that, today, geometry is taught as 'superior' metaphysics. For example, the class VI NCERT text in India declares that geometric points are invisible. This is in tune with the key aspect of formal math, namely the prohibition of the empirical. Western philosophy asserts that there is something wrong if one can actually see a geometric point. In practice, of course, students invariably work with visible dots, for there is

3 This string geometry, of course, has nothing whatsoever to do with modernday (metaphysical) string theory in physics! 
no other way. Teaching that reality is 'wrong' prevents students from applying common sense to objects they can see, as they may then not accept the authority of the text. If they are 'officially' allowed to learn from experience, someone will eventually notice that two visible dots can be connected by many straight lines which are all only approximately the same. Hence, colonial education teaches that practice and common sense are wrong and inferior! The only source of knowledge about the geometry of invisible points is the colonial authority of the text. Students are thus indoctrinated into accepting Western authority as the source of knowledge. Likewise, lines and planes must be invisibly thin ${ }^{4}$.

A line segment is defined in the NCERT class VI text as the curve corresponding to the 'shortest distance' between two points. Students learn to measure 'distance' empirically by superposition: they superpose a (straight) ruler on a visible (straight) line segment. This empirical process of superposition is also used in the original Elements, e.g. in the proof of its proposition 4 . However, the Western objection to this process, in the $19^{\text {th }}$ century was the basis of formalism. This makes geometry teaching incoherent;

${ }^{4}$ At a panel discussion at the University of Cape Town, I asked who in the hall had ever worked with invisible points. I likened the foolishness of invisible points to the foolishness of the emperor's invisible new clothes and burst out laughing. No one could respond, either from the panel or the audience, as they would have had to explain how to deal with invisible points. A racist reporter was incensed by my laughter and declared it a conspiracy to dismantle the remnants of racism. He claimed authoritatively that mathematicians 'routinely' work with invisible points, but did not explain how. Or why anyone must believe the white man's authority. What is surprising is that other colonised folk did not stand up and laugh with me at the coloniser's ridiculous claim to do some strange magic with invisible points. For example, how does one measure the distance between two invisible points? What if two people disagree about the exact location of the invisible points? And how would such a disagreement be settled? A question in my pre-test is this: do the invisible points stay in one place or do they move about at random, and what is the source of your knowledge about invisible points? If fixed, are they fixed relative to the earth, or absolute space, or another invisible point? A video of the panel discussion is posted at: https://www.youtube.com/watch?v=ckbzKfRIi6Q. 


\section{C.K. Raju}

if such an empirical process of superposition is permitted for distance measurement, there should be no objection to its use in the proof of the fourth proposition of the Elements: the side-angle-side (SAS) proposition.

Superposition, therefore, should not be declared an error as Russell did, and the school text does. But accepting superposition defeats Hilbert's (1950) whole programme on the foundations of geometry. Indeed, superposition is prohibited in Hilbert's geometry, which was hence called 'synthetic' since distance measurement is also prohibited. Recall that Hilbert sided with Russell and tried to 'correct' the author of the Elements who 'erred' in not conforming to the baseless church myth. Following Hilbert, school texts today treat SAS as a postulate not a theorem. They hide the fact (for obvious reasons) that this also prohibits distance measurement. Of course, Hilbert's (1950) synthetic geometry is convoluted; though length is not defined (to explain the seeming prolixity of the Elements), area is (to be able to prove the Pythagorean theorem). Defining area without defining length is an example of how any nonsense is possible in formal mathematics.

Under these varied influences, the geometry taught to school children today is an incoherent hotchpotch of empirical and synthetic geometry. This conceptual confusion is also reflected in the confusion between 'congruence' (Hilbert's term) and equality (the original term in the Elements). Few students or teachers can explain the difference, any more than they can explain where exactly an invisible point is located or why multiple invisible straight lines do not pass through two given points (as is seen to be the case with dots).

As a matter of fact, after the Sputnik 'crisis', a frightened US invested billions of dollars to revamp its STEM education and route it towards practical value. Subsequently, the School Mathematics Study Group (School Mathematics Study Group 1961) recommended the teaching of Birkhoff's axiomatic metric geometry (Birkhoff 1932), a geometry that stuck to axiomatics, but did not try to present a convoluted apologia for the apparent prolixity of the Elements, as Hilbert attempted. However, even though Birkhoff's geometry defines distance axiomatically, rather than empirically, it trivialises the Elements; the 'Pythagorean' theorem still has a shorter and simpler formal proof in metric geometry, unlike the Elements in which 46 intermediate propositions are used. Therefore, it too is not a valid interpretation of the Elements. The school text makes no attempt to differentiate between the four distinct geometries it mixes up, and does not even differentiate between the axiomatic definition of distance and the empirical definition. (Nor, of 
course, does it mention the Platonic connection between geometry and the religious notion of soul).

Thus, what is taught in schools in India today is an incoherent hotchpotch of four different and incompatible types of geometries: (1) Religious 'Euclidean' geometry; (2) Hilbert's synthetic geometry; (3) Birkhoff's axiomatic metric geometry; and (4) empirical compass box geometry. Students and even teachers do not seem to understand these incoherencies. Colonial education teaches them to accept everything on authority.

Later the class IX text teaches that a point cannot even be defined in other words, but it is not explained that an infinite regress arises only in formal math because it prohibits any reference to the empirical. Students are left befuddled, as it is not explained that the basic notions of point or line apply only to a fantasy world which is inconsistent with the real world. For example, in defining a straight line segment as the shortest distance between two points, it is not explained that this is not the real shortest distance between two points, on earth or in space.

It is no use offering the apologia that a straight line is approximately the shortest distance as the whole purpose of formalism is a claim to exactitude. No theory of approximation is taught which explains how to select one from the infinity of curved lines, which will also satisfy the criterion of 'approximately shortest'. Also, how can the degree of approximation be decided without reference to the empirical?

An angle is defined as something (what thing?) made by two straight lines. If so, why is a semi-circular protractor used to measure angles? Students are unable to explain. Does the size of a protractor matter? If not, why not? The pre-test shows that most students are unable to explain why. A protractor comes readymade, and students are also unable to explain how the circumference of the protractor is divided into 180 equal parts, or even what equal parts of a curved line mean. (One can superpose a string, but superposition is rejected. Defining the length of a curved line axiomatically requires calculus and a restriction to rectifiable arcs, which are beyond middle school).

The whole confusion is nicely topped up by the ritualistic inclusion in the geometry box of set squares and dividers which are almost never used. But all this teaches the main lesson of colonial education: that one must ritualistically imitate the master without asking why. Naturally, sensitive 


\section{C.K. Raju}

minds rebel; instead of declaring them 'bad' at math they should be congratulated for their resistance!

In contrast, in string geometry, there is simplicity and conceptual clarity. Points are visible dots. A straight-line segment between two points is obtained empirically by holding the string taut between two points. There is no need for infinite lines. The length of a curved line is naturally defined by superposition: placing the flexible string along the curve, and straightening it and measuring it (or using a flexible measuring tape).

An angle is now defined as the relative length of a curved arc. This removes the mystery of the protractor. The little arc used to denote an angle IS the angle. It also explains the radian measure of angles, as the length relative to the radius of the circle, which students habituated to the protractor and the degree measure of angles are typically unclear about. While the number today called $\pi$ is defined in the usual way as the ratio of the length of the circumference to the diameter, the length of the curved circumference is now meaningful, and there are easy ways to calculate that number.

The string is a superior replacement for the entire compass box (Raju 2009a). Thus, it replaces the ruler as above, but is superior since it can also be used to measure curved lines. It is a superior replacement for the protractor since one can directly measure the relative length of a curved arc, and thus get the angle in both degrees and radians. Holding one end of the string fixed enables a circle to be drawn; thus the string replaces the compass. By holding two fixed points, an ellipse may also be drawn, which is impossible with the instruments in a compass-box. As already noted, the set squares and dividers are irrelevant, and the string is superior as it teaches students to discard irrelevant Western ritual paraphernalia. Needless to add, a string can be made locally, unlike a compass box made of steel and plastic. It is low-cost and ecofriendly. By using the two-scale principle, a string can also be made highly accurate.

Note, further, that for actual practical measurements, such as the measurement of an agricultural field, a rope is a practical and superior instrument, unlike the toy instruments in a compass box, which are useful only on paper. Many other real-life practical applications, such as finding the time and the cardinal directions from the shadow of a gnomon, finding the radius of the Earth, and the local latitude and longitude, are explained in the draft text for Rajju Ganit which has been prepared as part of the experiments on teaching decolonised geometry in school. 
Because empirical methods are used, the proofs of propositions are straightforward and very easy. SAS is now a theorem not a duplicitous postulate (duplicitous because superposition continues in practice). The 'Pythagorean theorem' can be proved in one step. This makes irrelevant the exact order of the propositions in the Elements, an order required to be ritualistically followed (Taylor 1893) even by the revised Cambridge syllabus of the late $19^{\text {th }}$ century.

Approximations are an integral part of normal math. This is clear from the documentation in the sulba sutra-s. Thus, the Manava ${ }^{5}$ sulba sutra 10.10 (Sen \& Bag 1983) states the 'Pythagorean theorem' using square roots, though such a way of stating it is unheard of in Western tradition (but this is required to put the theorem to practical use). Note, first, that a right-angled triangle was regarded as half of a rectangle. (This seemingly trivial remark is important because Western historians have long asserted that Egyptians did not know what a right-angled triangle was (Gillings 1982; Appendix 5)). They certainly knew what a rectangle was. Now, if $a$ and $b$ are the two sides of rectangle, and $c$ is the diagonal then instead of $c^{2}=a^{2}+b^{2}$ the Manava sulba sutra states $c=\sqrt{a^{2}+b^{2}}$. Thus, if $a=1$, and $b=1$, we get $c=\sqrt{2}$. Square roots were known to Egyptians and Iraqis ('Babylonians'). Like Iraqi clay tablets, sulba sutra-s give a reasonably precise value of $\sqrt{2}$ (accurate to about five decimal places). A full-fledged algorithm for extracting square roots is documented in Indian tradition, and it was known that the algorithm does not terminate, so $\sqrt{2}$ can never be exactly evaluated. Consequently, all the sulba sutra-s call it savisesa, meaning 'with a remainder'.

The important thing is that the 'Pythagorean calculation' is not portrayed dishonestly as something exact (in a fantasy world, not explicitly declared a fantasy) but as only a useful approximation (in the real world), which can always be improved. This approximation is inevitable: on the earth, since it is curved, there is nowhere the 'Pythagorean theorem' holds exactly as

5 The whole text of the Manava sulba sutra is archived at http://ckraju.net/geometry/manava_shulba_sutra.pdf, while an English translation of 10.10 is posted at http://ckraju.net/geometry/translationManava-10.10.pdf. 


\section{C.K. Raju}

noted by the seventh century Indian mathematician Bhaskara $\mathrm{I}^{6}$, a thousand years before the 'official' advent of non-Euclidean geometry in the West. The purported exactitude of the Pythagorean theorem is delusional, and students ought to be informed about it.

To summarise, string geometry leads to (1) conceptual clarity; (2) ease in understanding; (3) superior and practical instruments; (4) a better understanding of mathematics as approximate and not exact.

Pedagogical experiments have been initiated to teach this at the level of class IX in school. The workshops for teachers were conducted in several locations across India. They involved both teachers and students; after explaining the teaching methodology to teachers, it was demonstrated with students. The teachers and students came from some 40 schools in Nasik. Likewise, many teachers from Karnataka and Tamil Nadu were involved in workshops conducted at Chamrajnagar and Gundulupete. The second step is for those teachers to teach school students. This is a little tricky to implement, especially in government-run schools, since the teachers will now be teaching that what they earlier taught was wrong! However, the Karnataka government, which supported one of the workshops, agreed that school texts must be corrected if they are wrong. Field trials are currently being conducted.

String geometry links directly to trigonometry and decolonised calculus (and infinite series for $\pi$ ) as it first developed in India. Thus, the string geometry course is a preparatory course for the course on calculus without limits.

\section{Decolonised Math 2: Calculus without Limits}

Current university calculus texts run into over a thousand pages, in large font and two columns ${ }^{7}$. By the end of the course a student has learnt very little.

Every student can rattle off that $\frac{d}{d x} e^{x}=e^{x}$ as one of the simplest formulae of calculus. But they cannot define $e^{x}$ (or even the $e$ or the $x$ in it!), nor can they

${ }^{6}$ Bhaskar (1963: I.25). See also (Raju 2007: 227).

${ }^{7}$ E.g. Thomas, Weir \& Giordano (2008) has $1228+34+80+14+6+6+$ xvi $(=1384)$ pages, in $11 \times 8.5$ inch size, while Stewart $(2007)$ has $1168+134+$ xxv pp. (= 1327) pages in 10 x 8.5 inch size with a supplemental CD. 
$\frac{d}{d x}$. Thus, what students are taught is merely the ritualistic use of
define
formulae they do not understand.

Some students do try to define the exponential function using an infinite series, but cannot explain how to sum an infinite series or define the sum as a limit, because this requires formal real numbers which are not taught in the fat calculus texts. For the same reason, since integrals and derivatives are formally defined as limits, students who have successfully completed a calculus course cannot define even the derivative or the integral. Clearly, all that they can do is to commit formulae to memory, and perform some tricks of symbolic manipulation, without understanding. They are effectively taught that they have no alternative but to accept mathematical authority localised in the West.

What the students take away are various 'intuitive' ideas, for example that the derivative is a tangent. But they were never taught what a tangent is, and are unable to define a tangent except by using an incorrect definition ${ }^{8}$ that a tangent line 'just touches' the curve at one point. It would be better to admit that the purpose of teaching calculus is not to impart knowledge but to indoctrinate students into the wrong idea that formal real numbers and limits are needed for calculus. The other important 'intuitive' idea they take away is about Western authority, supported by the false history that calculus was the achievement of Westerners (Newton and Leibniz). To drive home the point about Western superiority, the history of calculus is Christianised on the infamous doctrine of Christian Discovery; various Indian techniques are named 'Euler's' method, 'Stirling's formula' and so on (see e.g. Raju 2007). This false history is a key part of calculus teaching today to bolster Western authority by glorifying Westerners.

Thus, the colonised calculus student emerges in awe of Western autho-

${ }^{8}$ Some of these problems are brought out in the pre-test for the calculus without limits course, administered to undergraduate students, posted at http://ckraju.net/sgt/3-question-paper-pre-test-sgt.pdf. The pre-test administered to postgraduate students was different and delved into deeper (formalistic) issues such as the connection between the Riemann and Lebesgue integral, university-text definition of derivative and the Schwartz derivative, probability and measure, etc. 
rity, but ignorant of calculus, as per the colonial education plan. Recall that calculus is the major obstacle in the path of black university students who often come from poorer schools and have a weaker background in school-level calculus when they enter university. Decolonisation identifies the source of the difficulty of calculus as the junk metaphysics in it: the way junk metaphysics took Whitehead and Russell (1963) 378 pages to prove $1+1=2$. Eliminating this junk metaphysics makes calculus so easy that it can be learnt in five days regardless of the student's disciplinary background.

This ease of teaching calculus without limits has been repeatedly demonstrated by experiments to teach calculus in five days. The first was performed in Sarnath, in 2009 and reported the same year (Raju 2009b). The next experiment was performed with four batches of students in the Universiti Sains Malaysia, in 2010. These were stratified samples with one batch of postgraduate students, one of undergraduate pure math students, and one of undergraduate applied math students. The fourth batch consisted of undergraduate non-math students (Raju 2011b; 2011c). Subsequently, the experiment was repeated in many places, such as Ambedkar University Delhi (as a course on 'Calculus for Social Scientists'), in Tehran, and is currently being taught as a regular undergraduate course in SGT University, Delhi-NCR, with a batch of almost 75 engineering students. These pedagogical experiences have repeatedly confirmed that it is very easy to teach calculus without limits to a variety of students, even those who come from a weak school background.

Decolonisation begins with the observation that the key concern of the colonised should be the practical value of math, not with imitating colonial practices. As noted earlier, all practical value (such as sending a rocket to moon) is achieved today by using computers, and solving differential equations numerically, as in the original method of Indian calculus. Practical value was also the reason for the theft of calculus and its infinite series to derive accurate trigonometric values which Europeans badly needed as their dreams of wealth were tied to a major scientific challenge, the European navigational problem (which others had solved long ago). Therefore, decolonised calculus focuses on practical value.

This results not only in practical value, but in a huge gain in conceptual clarity. For example, $e^{x}$ is defined in decolonised calculus in a very simple and rigorous way as the solution of the differential equation $y^{\prime}=y$ with $y(0)=1$. (Most functions can be similarly defined). Using computers, 
students can easily calculate its value, graph it and understand its properties. This also drives home the point that 'real' numbers and limits are completely irrelevant to the practical value of calculus. Computers use floating point numbers and can never use formal real numbers.

Note the difference, however. Like traditional normal mathematics, decolonised calculus uses a realistic philosophy of inexactitude which I call zeroism. It is not the numerical solution which is erroneous; one can increase its accuracy but never achieve exactitude. This stands the Western philosophy of formal math on its head by declaring the claim of exactitude as erroneous and a mere metaphysical fantasy divorced from the real world.

Because decolonised calculus is so easy, it enhances practical value and enables students to solve much harder problems. For example, while the existing calculus texts are confined to integrals of elementary functions, calculus without limits easily goes beyond that and teaches non-elementary elliptic integrals. This is clear from a stock tutorial sheet ${ }^{9}$.

Such elliptic integrals arise in the first serious science experiment in school. The time period of oscillation of the simple pendulums depends upon the amplitude. But students are taught the wrong formula for its time period:

$$
T=2 \pi \sqrt{\frac{l}{g}}
$$

, where $l$ is the length of the string and $g$ the acceleration due to gravity. The excuse for teaching this wrong formula is simplification; the actual formula involves elliptic integrals, which are not taught as part of beginning university calculus courses. But since school teachers themselves do not learn elliptic functions, they treat the text book formula as exact and wrongly teach students that the time period is independent of the amplitude (Raju 2006b). The experiment performed by students (Raju 1999) easily shows the above formula to be wrong. Elliptic integrals are hardly the only example. What is the optimal angle of throw for a javelin? It is certainly not 45 degrees as I found out during an athletic competition! But explaining the theory requires a study of ballistics with air resistance. Likewise, the brachistochrone with air resistance becomes a school project (Raju 2012).

\section{Exactitude vs Inexactitude}

Decolonised calculus also sums infinite series in an easy and conceptually

${ }^{9}$ http://ckraju.net/sgt/Tutorial-sgt.pdf. 


\section{C.K. Raju}

clearer way than limits. Consider an infinite series such as $\sqrt{2}=1.414 \ldots=1+\frac{4}{10}+\frac{1}{100}+\frac{4}{1000}+\ldots$

How to sum such an infinite series exactly? If we add individual terms, each addition will take some time, so the entire infinite sum will take an eternity to sum. Therefore, an exact sum is physically impossible. For practical purposes, everyone accepts inexactitude as was done in traditional normal math; it is enough to know the value of $\sqrt{2}$ to 10 or 100 or 1000 decimal places. But, the West has been deluded into believing that mathematics is eternal truth and hence exact. Westerners, therefore, sought the exact sum, i.e., all the infinite decimal places. That is physically impossible, as simply writing down all infinite decimal places would take an eternity.

The West never understood the simpler Indian technique of using the 'avyakt' ganit of the $7^{\text {th }}$ century (Brahmagupta 1966), or how it was used to derive the first ever formula for the sum of the infinite geometric series (Raju 2007). (Finite geometric series are ancient, and found in the 'eye of Horus' fraction, and the Yajurveda 17.2.). An expository account is in Raju (2016a; 2016b).

Algebra was invented by Brahmagupta who referred to a polynomial such as $2 x+3$ as an 'avyakt' or 'unexpressed' number, as it acquires a value only after we assign a value to $x$. Naturally, there are also 'avyakt' fractions, $\frac{2 x+3}{3 x+4}$

such as

or what would today be called rational functions. Such rational functions constitute what is today called a non-Archimedean field (Moise 1963). That is, for $x>0$ we cannot find a definite natural number $n$ such that $x<n$. Such an $x$ is called infinite, and its reciprocal $\frac{1}{x}$ is called infinitesimal. (Note: infinitesimal does NOT mean imperceptible). In a non-Archimedean field there are no limits: instead of saying that $\lim _{n \rightarrow \infty} \frac{1}{n}=0$, we simply say that $\frac{1}{n}$

in infinitesimal when $n$ is infinite. There is no exactitude. However, we can get back 0 as an approximate limit, by neglecting infinitesimals, as in the 
philosophy of zeroism (Raju 2016c). Thus, for finite geometric series, simple algebra tells us that $(1-x)\left(1+x+x^{2}+\ldots+x^{n}\right)=1-x^{n+1}$ so the sum is $1+x+x^{2}+\ldots+x^{n}=\frac{1-x^{n+1}}{1-x}$ . If the common ratio $x<1$ then for infinite $n$, $x^{n+1}$ is infinitesimal and can be discarded. This gives the formula for the sum of an infinite geometric series. Easy, isn't it?

Note that this involves a different concept of infinity from that used in the West; no Western magic happens at infinity to result in metaphysical exactitude. All we do is continue the normal practice of accepting inexactitude and discarding small numbers, but at infinity we discard infinitesimals.

By decolonising calculus, we thus remove all major conceptual difficulties of university calculus, and enable students to solve harder practical problems.

\section{Advanced Applications}

The colonised mind is full of superstitious fears of some great calamity if the master is disobeyed. It is therefore important to reiterate that decolonised calculus also results in better science. Newton's misunderstanding of calculus led to the conceptual confusion about flowing time in his physics and related fluxions in his mathematics. This has been corrected recently, along with the theory of gravitation.

However, let us look at some simpler aspects of the mischief created by colonial calculus. The equations of physics are formulated as differential equations. The use of the colonial calculus, and formal 'real' numbers results in something strange: it forces time, in physics, to be like the 'real' line, simply to enable the equations to be written down. The strange thing is that no physics went into this conclusion which is derived purely from metaphysics. (The differential equations of physics are local and do not depend on the global topology of time.)

This 'conclusion' about superlinear time does great damage to original African (and Egyptian, and Indian) religious beliefs (Raju 2003) which, like the Platonic belief in the soul, are based on the concept of quasi-cyclic time. (Early Christianity had the same belief which was changed by the post-Nicene church to suit its politics against equity by pronouncing a curse on the notion 


\section{C.K. Raju}

of quasi-cyclic time (Raju 2003)). Recall, also, that the first creationist conflict took place in mathematics not biology, when in the sixth century John Philoponus wrote On the Eternity of the World: Against Proclus (who had said time was 'cyclic'). Philoponus' argument was that this would be contrary to the doctrine of creation described in the scriptures. This interest in eternity and the doctrine of one-time creation (Raju 2015) is a strong but little-known reason why the West wants to persist with its bad understanding of calculus.

More recently, Hawking and Ellis (1973) claimed that science had proved the truth of creation (in the Judeo-Christian sense): the laws of physics must break down at the moment of creation. This conclusion is the bottom line of their book: 'The actual point of creation, the singularity, is outside the presently known laws of physics' (Hawking \& Ellis 1973: 364).

In fact (Raju 2003), Hawking \& Ellis introduced a postulate - their 'chronology condition'. There is no way to empirically verify that postulate about time. The postulate is pure metaphysics, as is their conclusion about creation. Very few knowledgeable people will understand that this postulate corresponds exactly to the metaphysics of the church's politically motivated curse on 'cyclic' time against early Christianity. Hawking and Ellis justified their postulate using exactly Augustine's bad arguments against quasi-cyclic time.

Note that a big bang is not necessarily a moment of creation, so a singularity is required to assert anything like a moment of creation. For laypersons who do not understand the creationist meaning of a singularity, Hawking (1988) explained a singularity thus:

At the big bang and other singularities, all the laws [of physics] would have broken down, so God would still have had complete freedom to choose what happened and how the universe began (Hawking 1988).

These conclusions that a particular notion of god and creation were backed by science were made quite explicit by Tipler:

Theology is a branch of physics, ... physicists can infer by calculation the existence of God and the likelihood of the resurrection of the dead to eternal life ... [T] he central claims of Judeo-Christian theology are in fact true, ... these claims are straightforward deductions of the laws of physics (Tipler 1995: ix). 
Tipler emphasises that we must accept this as 'mainstream' physics, derived from singularity theory, on the authority of the reputed journal Nature, in which he has published several articles.

This is an example of how formal math enables all sorts of Western superstitions to be portrayed as 'top-level science'. We are asked to believe these superstitions on the authority of science and few understand the twisted political purposes they serve.

But how exactly does a singularity correspond to a 'moment of creation'? There are other Western superstitions here, for example, about the 'laws of physics'. This superstition was first articulated by Thomas Aquinas in his Summa Theologica that 'God rules the world with eternal laws of nature', and I have examined it elsewhere. This is what enables Hawking and Ellis to assign a cosmic significance to the supposed breakdown of the 'laws' of nature.

But how exactly do we know that there is any 'breakdown' of those 'laws'? All that Hawking and Ellis proved, even within inferior formal math, is that some geodesics intersect at a singularity. At best, this means that smooth solutions of the differential equations of general relativity cannot be extended beyond a singularity. But why should solutions be smooth? Non-smoothness arises in many common situations such as a shock wave (Raju 1982a; 1982b). It is only in university calculus (according to which a differentiable function must be continuous) that smoothness is required because the differential equations of physics do not make sense at a discontinuity.

Decades ago when I still taught formal math I used to teach this theorem (differentiability implies continuity) in a beginning course on what is called 'Real Analysis'. Curiously, at the same time, in a more advanced course on 'Advanced Functional Analysis' I taught the exact opposite: that most discontinuous functions may be differentiated infinitely often, using the definition of derivative according to what is called the Schwartz theory of distributions (Rudin 1973). (Fortunately, there were no students common to both courses!).

The point is that it is pretentious to claim that the 'laws' of physics break down at a singularity; they do not. Even within formal math one can make sense of the differential equations of physics using the Schwartz theory and something called non-standard analysis (Raju 1989). This is technical and beyond the reach of even most formal mathematicians, and also solves a related difficulty in quantum field theory (Raju 1983). But the only active feature of non-standard analysis required for this solution is non-Archimedean 


\section{C.K. Raju}

arithmetic, already present within decolonised calculus. So the 'laws' of physics can be saved from a breakdown if we use normal math (Raju 2007). Thus, decolonising calculus also helps to understand and block the colonial trick of passing off politically convenient metaphysics ('creation') as science.

\section{Advancing Decolonisation: Exposing Colonial Shenanigans}

At a panel discussion (or rather debate) on decolonising mathematics and science at the University of Cape Town (UCT), I submitted an advance abstract ${ }^{10}$ where I explicitly proposed to discuss these technical and political issues separately in the mathematics department at UCT. Ellis has long been in that department, and has received the million dollar Templeton award for mixing religion with science. He seemed reluctant to engage in open debate. It also appeared that the UCT math department lacks the technical skills in formal math required for such a debate.

What would the church do if it were asked to openly debate its belief in virgin birth on which its ethical system is founded? Obviously it would do what it has done through the ages: try to control the narrative by attacking the challenger as a 'heretic' and burn him. Ellis and his student Jeff Murugan did something similar, planting falsehoods about me in the press and effectively mobilising a racist lynch mob. Had there been the slightest grain of truth in what they said, they would have spared an hour to debate it with me, and then gone to the press - but they knew a debate would expose them and the tricks used to promote superstitions as science through formal math. They were afraid of the resulting unending laughter of a mass of the colonised.

The non-violent transition of power in South Africa means that a large number of racists and racist stooges continued seamlessly in positions of power and authority. They will resist decolonisation which challenges that continuing power. Therefore, they are back to the old colonial tricks of retaining power by telling lies. The colonised need always to remember that the first step in decolonisation is to distrust Western authority; not only Rhodes, but all colonial authority must fall. Those who flourished during apartheid were those who helped the coloniser, not the colonised. This is true even in subjects like mathematics and science, which are supposedly, politically neutral. An easy

${ }^{10} \mathrm{http} / / / \mathrm{ckraju} . n e t / p a p e r s /$ uct-panel-decolonising-science-ckr-summary.pdf. 
way to challenge authority in this case is to be highly sceptical and question it relentlessly. Why does Ellis, who flourished under apartheid, demand that his authority be trusted? Can Murugan explain his blatant falsehood about 'Bantuization'? How can it be reconciled with the demonstrated ability of students to solve elliptic integrals with the decolonised calculus? Those trying to derail the decolonisation agenda with brazen falsehoods should not only not be trusted, but criminally prosecuted as cheats as they misuse their authority to mislead a large number of people whose future interests depend critically upon decolonisation.

\section{References}

Bhaskara, I. 1963. Laghu-Bhaskariya. Shukla, K.S. (ed. \& trans.) Lucknow: Department of Mathematics and Astronomy, Lucknow University.

Birkhoff, G.D. 1932. A Set of Postulates for Plane Geometry, Based on Scale and Protractor. Annals of Mathematics 33:329 - 345.

https://doi.org/10.2307/1968336

Brahmagupta 1966. Brahmagupta's Brahmasphutasiddhanta. Sharma, A.R.S. (ed. \& trans.). Delhi: Indian Institute of Astronomy and Sanskrit Research. Clagett, M. 1999. Ancient Egyptian Mathematics. Philadelphia: American Philosophical Society.

Colebrooke, H.T. 1817. The Algebra of Brahmegupta and Bhascara. London: John Murray.

Gillings, R.J. 1982. Mathematics in the Time of the Pharaohs. New York: Dover Press.

Hawking, S. 1988. A Brief History of Time. New York: Bantam.

Hawking, S. \& G.F.R. Ellis 1973. The Large Scale Structure of Spacetime.

Cambridge: Cambridge University Press.

https://doi.org/10.1017/CBO9780511524646

Hilbert, D. 1950. The Foundations of Geometry. La Salle: The Open Court Publishing Co.

Kant, I. 1996. Critique of Pure Reason. Chicago: Encyclopedia Britannica.

Lalla (Sisyadhivrddhidatantra) 1981. शिष्यधीवृद्धिद. Chatterjee, B. (ed. \& trans.). Delhi: Indian National Science Academy.

Moise, E.A. 1963. Elementary Geometry from an Advanced Standpoint. New York: Addison-Wesley. 
Raju, A. 2012. A Simple Way to Solve the Brachistochrone Problem with Resistance. Physics Education (India) 28,3:1 - 6. Available at:

http://physedu.in/uploads/publication/3/65/Archishman Brachistochrone 13July.pdf.

(Accessed on 13 July 2013.)

Raju, C.K. 2017. Mathematics and Censorship. Available at:

https://kafila.online/2017/06/25/mathematics-and-censorship-c-k-raju/.

(Accessed on 25 June 2017.)

Raju, C.K. 2016a. Calculus. In Encyclopedia of Non-Western Science, Technology and Medicine. Dordrecht: Springer. Available at:

http://ckraju.net/papers/Springer/ckr-Springer-encyclopedia-calculus-1final.pdf. (Accessed on 12 October 2018.)

DOI: https://doi.org/10.1007/978-94-007-3934-5_9555-2

Raju, C.K. 2016b. Calculus Transmission. In Encyclopedia of Non-Western Science, Technology and Medicine. Dordrecht: Springer. Available at: http://ckraju.net/papers/Springer/ckr-Springer-encyclopedia-calculus-2final.pdf

(Accessed on 12 October 2018.)

DOI: https://doi.org/10.1007/978-94-007-3934-5_10326-1

Raju, C.K. 2016c. Zeroism. In Encyclopedia of Non-Western Science, Technology and Medicine. Dordrecht: Springer. Available at:

http://ckraju.net/papers/Springer/zeroism-springer-f.pdf.

(Accessed on 12 October 2018.)

DOI: https://doi.org/10.1007/978-94-007-3934-5_10248-1

Raju, C.K. 2015. Eternity and Infinity: The Western Misunderstanding of Indian Mathematics and its Consequences for Science Today. American Philosophical Association Newsletter on Asian and Asian American Philosophers and Philosophies 14,2:27 - 33. Available at:

http://ckraju.net/papers/Eternity-and-infinity-Pages-from-APA.pdf.

(Accessed on 03 March 2016.)

Raju, C.K. 2011a. Probability in Ancient India. In Dov, M., P.T. Gabbay \& J.

Woods (eds.): Handbook of the Philosophy of Science. Amsterdam:

Elsevier. Available at: http://www.ckraju.net/papers/Probability-in-

Ancient-India.pdf. (Accessed on 13 February 2012.)

https://doi.org/10.1016/B978-0-444-51862-0.50037-X

Raju, C.K. 2011b. Teaching Mathematics with a Different Philosophy, 1: Formal Mathematics as Biased Metaphysics. Science and Culture 77:275 
- 280. Available at: http://www.scienceandculture-isna.org/July-aug2011/03\%20C\%20K\%20Raju.pdf. (Accessed on 13 February 2012.)

Raju, C.K. 2011c. Teaching Mathematics with a Different Philosophy, 2: Calculus without Limits. Science and Culture 77:281 - 286. Available at: http://www.scienceandcultureisna.org/July-aug-

2011/04\%20C\%20K\%20Raju2.pdf.

(Accessed on 13 February 2012.)

Raju, C.K. 2009a. Towards Equity in Math Education 2. The Indian Rope Trick. Bharatiya Samajik Chintan (New Series) 7,4:265 - 269. Available at: http://ckraju.net/papers/MathEducation2RopeTrick.pdf.

(Accessed on 07 July 2010.)

Raju, C.K. 2009b. Calculus without Limits: Report of an Experiment. Paper Presented at The $2^{\text {nd }}$ People's Education Congress. Mumbai: Homi Bhabha Centre, TIFR 5 - 8 October 2009. Available at:

http://ckraju.net/papers/calculus-without-limits-paper-2pce.pdf.

(Accessed on 12 October 2018.)

Raju, C.K. 2008. Logic. In Encyclopedia of Non-Western Science, Technology and Medicine. Dordrecht: Springer. Available at:

http://ckraju.net/papers/Nonwestern-logic.pdf.

(Accessed on 12 October 2018.)

https://doi.org/10.1007/978-1-4020-4425-0_8706

Raju, C.K. 2007. Cultural Foundations of Mathematics: The Nature of Mathematical Proof and the Transmission of Calculus from India to Europe in the $16^{\text {th }} C$. CE. New Delhi: Pearson Longman.

Raju, C.K. 2006a. The Religious Roots of Mathematics. Theory, Culture \& Society 23:95 - 97.

https://doi.org/10.1177/0263276406023002147

Raju, C.K. 2006b. Time: What is It that It can be Measured? Science \& Education 15,6:537 - 551.

https://doi.org/10.1007/s11191-005-5287-z

Raju, C.K. 2003. The Eleven Pictures of Time: The Physics, Philosophy, and Politics of Time Beliefs. New Delhi: Sage.

https://doi.org/10.4135/9788132102854

Raju, C.K. 2001. Computers, Mathematics Education, and the Alternative Epistemology of the Calculus in the Yuktibhāșā. Philosophy East and West 51,3:325 - 362.

https://doi.org/10.1353/pew.2001.0045 


\section{C.K. Raju}

Raju, C.K. 1994. Time: Towards a Consistent Theory. Dordrecht: Springer. https://doi.org/10.1007/978-94-015-8376-3

Raju, C.K. 1989. Distributional Matter Tensors in Relativity. In Blair, D., M.J. Buckingham \& R. Ruffini (eds.): Proceedings of the Fifth Marcel Grossman Meeting on General Relativity. Singapore: World Scientific arXiv: 0804.1998. Available at: https://arxiv.org/abs/0804.1998

Raju, C.K. 1983. On the Square of $\mathrm{x}^{-\mathrm{n}}$. Journal of Physics A: Mathematical and General 16:3739 - 3753.

https://doi.org/10.1088/0305-4470/16/16/013

Raju, C.K. 1982a. Junction Conditions in General Relativity. Journal of Physics A: Mathematical and General 15:1785 - 1797.

https://doi.org/10.1088/0305-4470/15/6/017

Raju, C.K. 1982b. Products and Compositions with the Dirac Delta Function. Journal of Physics A: Mathematical and General 15:381-396.

https://doi.org/10.1088/0305-4470/15/2/011

Raju, S. 1999. Pendulum Project. Available at:

http://ckraju.net/11picsoftime/pendulum.pdf.

(Accessed on 12 October 2018.)

Rhodes Must Fall Movement Oxford 2018. Rhodes Must Fall: The Struggle to

Decolonise the Racist Heart of Empire. London: Zed Books.

Rudin, W. 1973. Functional Analysis. New Delhi: Tata McGraw Hill.

Russell, B. 1897. An Essay on the Foundations of Geometry. Cambridge:

Cambridge University Press.

Russell, B. 1917. Mysticism, Logic, and Other Essays. London: George Allen and Unwin. https://doi.org/10.5962/bhl.title.19117

Sen, S.N. \& A.K. Bag 1983. The Sulbasutras of Baudhayana, Apastamba, Katyayana and, Manava. New Delhi, India: Indian National Science Academy.

School Mathematics Study Group 1961. Geometry. New Haven: Yale University Press.

Stewart, J. 2007. Calculus: Early Transcendentals. Delhi: Thomson Books. Suri, H. 2000. षटदर्शन समुच्चय. Jain, M. (ed. \& trans.) New Delhi: Bharatiya Jnanapeeth.

Taylor, H.M. 1893. Euclid's Elements of Geometry. Cambridge: Cambridge University Press.

Thomas, G.B., M.D. Weir \& F.R. Giordano 2008. Thomas' Calculus. New Delhi: Dorling Kindersley. 
Tipler, F.J. 1995. The Physics of Immortality, Modern Cosmology, God and the Resurrection of the Dead. London: Macmillan.

Whitehead, A.N. \& B. Russell 1963. Principia Mathematica, Volume 1. Cambridge: Cambridge University Press.

C.K. Raju Indian Institute of Education Mumbai University, Kalina Campus Mumbai $\underline{\text { ckr@ckraju.net }}$ 


\section{C.K. Raju}

\section{Tutorial-1}

\section{Calculus without Limits}

1. (a) Define an angle

(b) Convert $32^{\circ}$ into radians.

(c) Convert 0.78 radians to degrees.

2. (a) Solve the ODE $y=y$ with $y(D)=1$.

(b) Hence, calculate the value of $e$.

(c) Define the exponential function $E^{x}$.

3. (a.) Convert the second order ODE $y^{\prime \prime}=-y$ to two first order ODEs.

(b) Solve the system of two simultaneous $\mathrm{ODE}$ s with the initial data. $y(0)=$ D, $\sqrt{ }(\mathrm{D})=1$.

(c) Calculate $\pi$ correct to 4 decimal places.

4. (a) Define the function $\cos (x)$.

(b) Calculate $\cos \left(42^{\circ}\right)$.

5. (a) The equation for damped hamonic motion is often written as

$$
\ddot{y}=-k^{2} y-b \dot{y}
$$

- Convert this to a system of $2 \mathrm{ODEs}$, and solve with the initial data. $y(0)=0$, and $k=1$, and $b=0.1$.

(b) How does the solution change if we use the initial data $y(0)=1$ ?

(c) Re calculate the solution for $b=0.2, b=0.3$. Can you guess the solution for a general $b$ ?

6. The equation of motion for a simple pendulum is

$$
y^{\prime 2}=\left(1-y^{2}\right)\left(1-k^{2} y^{2}\right) \text {. }
$$

The substitutions

$$
\begin{aligned}
y & =\operatorname{sn}(x)=y_{1} \\
1-y^{2} & =\operatorname{cn}^{2}(x)=y_{2}^{2} \\
1-k^{2} y^{2} & =\mathrm{dn}^{2}(x)=y_{3}^{2} .
\end{aligned}
$$


converts this to 3 equations in Jacobi's form

$$
\begin{aligned}
& y_{1}=y_{2} y_{3}, \\
& y_{2}=-y_{3} y_{1}, \\
& y_{3}=-k^{2} y_{1} y_{2},
\end{aligned}
$$

Solve the above equations with the initial data $y_{1}(D)=D, y_{2}(D)=1$, $y_{3}(0)=1$, and parameter $k=0.4$.

(b) Compare the Jacobian elliptic function $\operatorname{sn}(x)$ with $\sin (x)$.

(c) The time period of the simple pendulum is the first zero of $\operatorname{sn}(x)$. Calculate it.

7. (a.) Van der Pol's equation is

$$
y^{\prime \prime}+t\left(y^{2}-1\right) y^{\prime}+y=0,
$$

Convert this equation to two first order ODEs.

(b) Solve the resulting $O D E s$ for $y(D)=2$, and $y(D)=D$, and paraneter value $t=1$

8. (a.) Solve the systen of equations for the Lorenz model

$$
\begin{aligned}
& y_{1}^{\prime}=-\sigma y_{1}+\sigma y_{2}, \\
& y_{2}^{\prime}=-y_{1} y_{3}+r y_{1}-y_{2}, \\
& y_{3}^{\prime}=y_{1} y_{2}-b y_{3} .
\end{aligned}
$$

for the parameters $b=\frac{3}{3}, \sigma=10, T=28$, and initial daba $y_{1}=8, y_{2}=-8$, $y_{3}=27$, over the range $[2,2]$.

(b) Draw the resulting phase plots.

(c) Switch to $3 \mathrm{~d}$ view, and animate.

9. A ball is thrown upwards at an angle $\theta$ from a height of 10 meters. Assum ing a simple model of air resistance proportional to velocity, and assuming its coordinates at any instant are $\left(y_{1}, y_{2}\right)$, the equations of motion are given by

$$
\begin{aligned}
& y_{1}=y_{3}, \\
& y_{2}=y_{4}, \\
& y_{3}=-\frac{b}{m} y_{3}, \\
& y_{4}=-g-\frac{b}{m} y_{4} .
\end{aligned}
$$

where $b$ is the drag coefficient and $m$ is the mass of the ball.

(a) The mass of a cricket ball is 155.9 gram and the mass of a tennis ball is 58.5 gram. Assume $b=0.01$. Both balls are thrown with the same velocity $10 \mathrm{~m} / \mathrm{s}$, a.t an angle of $45^{\circ}$. Which ball will travel further? By how much?

(b) If the angle of throw is changed to $44^{\circ}$ (for either ball) will it travel a larger or a smaller distance? 